\title{
The evaluation of cefuroxime in the prevention of postoperative infection
}

\author{
R. S. CROTON† \\ F.R.C.S. \\ D. SYKES $\dagger$ \\ M.D., F.R.C.S. \\ J. TREANOR $\dagger$ \\ F.R.C.S. \\ P. WAKE $\dagger$ \\ F.R.C.S. \\ H. T. GREEN $†$
M.D. \\ M. A. KNOWLES $\dagger$ \\ M.B., Ch.B. \\ L. A. EILON* \\ B.Pharm. \\ $†$ Walton Hospital, Liverpool, and *Glaxo Group Research, Greenford
}

\begin{abstract}
Summary
Patients undergoing biliary surgery received either $750 \mathrm{mg}$ cefuroxime i.m. with the premedication and then 8 hourly for 3 days ((group $A$ ) or $1.5 \mathrm{~g}$ cefuroxime i.v. at the time of induction of anaesthesia (group B) or no treatment (group C). Wound infections occurred in 3 out of 35 patients in group A, 1 out of 40 patients in group $B$ and 11 out of 39 patients in group $C$ (group $B$ significantly different than group $C, P<0.05)$. Eight patients $(23 \%)$ in group A, $10(25 \%)$ in group B and $13(33 \%)$ in group $C$ had chest complications. Cefuroxime was effective in the reduction of wound sepsis following biliary surgery and $1.5 \mathrm{~g}$ i.v. administered during induction of anaesthesia is the dosage of choice. The incidence of chest infection tended to be lower in patients receiving cefuroxime but many more patients would have to be studied for a conclusive result.
\end{abstract}

\section{Introduction}

Cefuroxime is a broad spectrum injectable antibiotic which is active against both Gram-positive and Gram-negative organisms being stable to most $\beta$-lactamases produced by bacteria (O'Callaghan et al., 1976). It is effective in the treatment of a wide variety of infections, but its value in the prophylaxis of infection associated with abdominal surgery is still to be established. Other antibiotics have been used for prophylaxis in various dosage regimens and it is unclear which regimen is most appropriate (Strachan et al., 1977; Morran, McNaught and McCardle, 1978; Stone et al., 1976). This trial was designed to determine the effect of cefuroxime sodium on the incidence of wound and chest infection following biliary surgery, and 2 dosage regimens were compared with an untreated control group.

\section{Materials and methods}

\section{Patients}

Patients undergoing elective biliary surgery were entered into the trial after giving their informed consent. Those who had received antibiotics in the 2 weeks before surgery or who were allergic to cephalosporins or penicillins were excluded. The patients were randomly allocated to one of 3 groups. Patients in group A received $750 \mathrm{mg}$ cefuroxime i.m. with the premedication and 8-hourly for 3 days after operation; those in group B received a single dose of cefuroxime $1.5 \mathrm{~g}$ i.v. at induction of the anaesthetic and those in group $\mathrm{C}$ had no treatment.

\section{Assessment of infections}

The wounds were assessed daily while the patient was in hospital by a clinician who was unaware which treatment the patient had received. The presence of erythema, serous discharge and pus were recorded. Patients were classified as having wound infections if pus or serous discharge was present. Any late infections presenting during follow-up were also recorded.

The presence or absence of sputum was recorded before, and on the 2nd and 5th day after, surgery. Sputum was graded as either mucoid, mucopurulent or purulent. Chest X-rays were carried out before, and between the 3rd and 5th days after, operation, in patients where it was clinically indicated. Patients were classified as having chest complications if mucopurulent or purulent sputum was present after surgery and/or if there was a deterioration in the chest X-ray.

Infections were treated according to the usual clinical practice. 


\section{Bacteriology and cefuroxime estimations}

Samples of sputum and swabs from infected wounds were taken and subjected to routine microbiological examination.

Bile and serum samples were taken from some patients immediately after removal of the gallbladder. The cefuroxime concentrations in these samples were estimated by large plate microbiological assay as described by O'Callaghan and Harding (1977).

\section{Results}

Patients

One hundred and twenty-four patients entered the trial. However 10 patients were not included in the analysis: 7 in group A did not complete the 3-day course of cefuroxime (this was mainly because of pain on injection but one patient developed an urticarial rash), one patient in group B died of a pulmonary embolus 3 days after surgery and 2 patients in group $\mathrm{C}$ were given antibiotics in error. Thus, the analysis was carried out on results from 35 patients in group A and 40 patients in group B and 39 patients in group $C$.

The groups were well matched for weight, height and age although there was an uneven distribution of males and females (see Table 1). They were also well matched for numbers of smokers in each group and patients with obstructive jaundice.

TABle 1. Patient details

\begin{tabular}{llccc}
\hline Group & & A & B & C \\
& & (i.m.) & (i.v.) & (control) \\
\hline Total & 35 & 40 & 39 \\
Male & 8 & 8 & 15 \\
Female & & 27 & 32 & 24 \\
Weight (kg) & average & 66 & 64 & 67 \\
& range & $48-108$ & $44-97$ & $44-95$ \\
Height (cm) & average & 165 & 162 & 165 \\
& range & $148-180$ & $150-153$ & $149-182$ \\
Age (years) & average & 54 & 49 & 50 \\
& range & $24-78$ & $22-75$ & $20-77$ \\
\hline
\end{tabular}

There was no difference in the groups with respect to type of skin preparation, type of incision, suture material, length of scar or duration of surgery. However, more patients in group $\mathrm{C}$ underwent exploration of the common bile duct than did those in the other 2 groups.

\section{Infections}

Three patients $(9 \%)$ in group A, one $(2 \%)$ in group $B$ and $11(28 \%)$ in group $C$ had wound infections (group B was significantly different from group C, $P<0.05$ partition $\chi^{2}$ test (Everitt, 1977). The type of surgery which resulted in wound infections is detailed in Table 2. One patient in group $\mathrm{C}$ had a septicaemia and another had a late infection.
TABLE 2. Operations (figures in parentheses show the number of patients with wound infections)

\begin{tabular}{|c|c|c|c|}
\hline Group & $\underset{\text { (i.m.) }}{A}$ & $\stackrel{\text { B }}{\text { (i.v.) }}$ & $\underset{\text { (control) }}{\mathrm{C}}$ \\
\hline $\begin{array}{l}\text { Cholecystectomy } \\
\text { Cholecystectomy + exploration }\end{array}$ & $25(2)$ & $33(1)$ & $25(5)$ \\
\hline $\begin{array}{l}\text { CBD with stones } \\
\text { Cholecystectomy }\end{array}$ & $5(1)$ & $4(0)$ & $8(5)$ \\
\hline CBD without stones & $3(0)$ & $2(0)$ & $5(1)$ \\
\hline Other & $2(0)$ & $1(0)$ & $1(0)$ \\
\hline
\end{tabular}

$\mathrm{CBD}=$ common bile duct.

Exploration of the common bile duct in the $\overrightarrow{\vec{J}}$ presence of stones was associated with an increased $\omega_{\sigma}$ risk of wound infection. Eight patients in group $C D$ underwent such a procedure, of whom 5 had wound 3 . infections; whereas there were only 6 wound infec-or tions from 31 patients in group $\mathrm{C}$ who did not have bile duct stones. One patient out of 9 in groups $A$ and ${ }_{\infty}$ $B$ had a wound infection after exploration of the $\omega$ common bile duct when stones were present.

No one organism was consistently isolated from 으 the infected wounds: Staphylococcus pyogenes was most frequently isolated and the other isolates were $c$ coliforms.

Eight patients in group A (23\%), 10 in group $B$ $(25 \%)$ and 13 in group $C(33 \%)$ had chest comp $\infty$ cations. In most cases no organism could be isolated. and from the remainder the most frequently isolated organism was Haemophilus influenzae either alone ơ with Streptococcus pneumoniae.

All the infections are summarized in Table 3.

TABLE 3. Postoperative infections

\begin{tabular}{lccc}
\hline Group & $\mathrm{A}$ & $\mathrm{B}$ & $\mathrm{C}$ \\
& (i.m.) & (i.v.) & (control) \\
\hline Chest complications & 8 & 10 & 13 \\
Wound infections & 3 & 1 & 11 \\
Urinary tract infection & 1 & 2 & 1 \\
Other & 0 & 1 & 1 \\
\hline
\end{tabular}

\section{Cefuroxime concentrations}

Cefuroxime concentrations were assessed in $56 \frac{3}{3}$ patients who had a cholecystectomy, 26 from group 을 $A$ and 30 from group B. The results are presented in Fig. 1. Cefuroxime bile concentrations averaged $8.5 \mathrm{mg} / \mathrm{l}$ for patients in group $A$ and $24.6 \mathrm{mg} / \mathrm{l}$ for patients in group B. The cefuroxime concentrations $\sigma$ in the serum taken at the same time as the bile $N$ samples averaged $21.5 \mathrm{mg} / 1$ and $67.7 \mathrm{mg} / \mathrm{l}$ for patient $\underset{\mathrm{N}}{ }$ in group A and B respectively.

\section{Discussion}

These results show that a $1.5 \mathrm{~g}$ i.v. dose of cefuroxime given during the anaesthetic induction greatly reduces the incidence of wound infection associated with biliary surgery, and that there is no benefit in continuing the treatment after operation. 
Burke (1961) showed in a series of animal experiments that the effective period of antibiotic protection was at the time of inoculation of the bacteria, therefore a postoperative course of antibiotic would

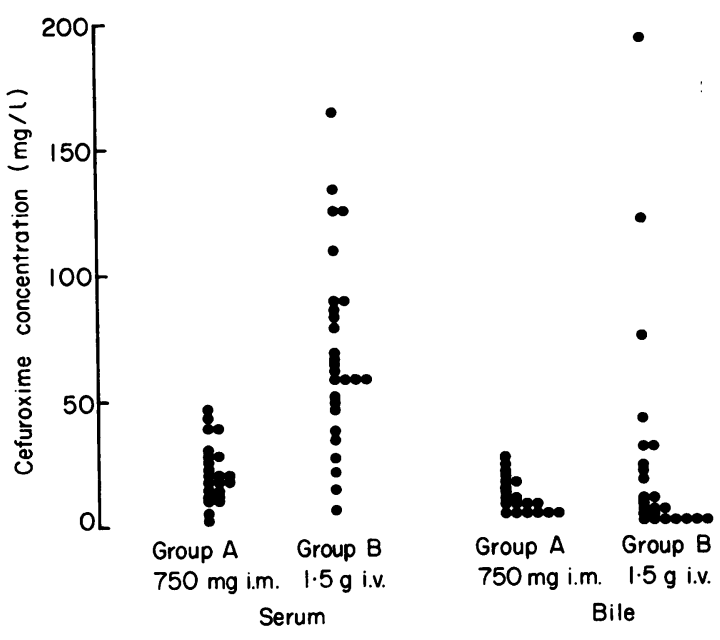

FIG. 1. Serum and bile cefuroxime concentrations.

not be expected to reduce the incidence of wound infection. Strachan et al. (1977) and Stone et al. (1979) have also shown that there is no clinical benefit from the postoperative administration of other cephalosporins. The present authors have shown a difference between the 2 antibiotic treatment groups and this may be related to the serum cefuroxime concentration during surgery; the serum concentration from the i.v. $1.5 \mathrm{~g}$ dose was considerably higher than that of the $750 \mathrm{mg}$ i.m. group.

Although the incidence of wound infection in the control group was rather high at $28 \%$, a broad definition of wound infection, as described by Polk and Lopez-Mayor (1969), which includes wounds discharging serum as well as pus, was used. This is justified because the incidence of serous discharge was unevenly distributed throughout the 3 treatment groups and it was considered that the antibiotic influenced the occurrence.

The question of prophylaxis against chest infection is much less clear cut. One of the major problems in this area is to distinguish between true infection and atelectasis (Editorial, 1977). Atelectasis is common after upper abdominal surgery and would not be affected by antibiotics. This problem is reflected in the widely varying incidence of postoperative chest complications reported by various authors: $81 \%$ by Lazlo et al. (1973); $32 \%$ by Presley and Alexander-Williams (1974); $86 \%$ by Collins, Darke and Knowelden (1968); 75\% by Hansen, Drablos and Steinert (1977); $21 \%$ by Wightman (1968); $47 \%$ by Morran and McArdle (1980); and $33 \%$ in the present study. This depends on the criteria used for assessment and would explain why the present study failed to show any benefit for the antibiotic group.

Cefuroxime has been shown to reduce greatly the incidence of wound infection after biliary surgery, and $1.5 \mathrm{~g}$ given i.v. is the dosage of choice. The value of cefuroxime in the prophylaxis of chest infections is not clear; more accurate methods to distinguish between chest infections and atelectasis must be used before further progress can be made.

\section{Acknowledgments}

We would like to thank Mrs Lynne Thornton for administration of the trial; Mr M. I. J. Hogg and Miss Vivian Haskett for help with analysing the results and Miss J. M. Scheidegger for secretarial help.

\section{References}

BURKE, J.F. (1961) The effective period of preventative antibiotic action in experimental incisions. Surgery, 50, 161.

Collins, C.D., Darke, C.S. \& Knowelden, J. (1968) Chest complications after upper abdominal surgery: their anticipation and prevention. British Medical Journal, 1, 401.

EDITORIAL (1977) Post-operative atelectasis. Lancet, ii, 965.

EVERITT, B.S. (1977) The Analysis of Contingency Tables, 1 st edn, p. 44. Chapman and Hall, London.

Hansen, G., Drablos, P.A. \& Steinert, R. (1977) Pulmonary complications, ventilation and blood gases after upper abdominal surgery. Acta anaesthesiologica scandinavica, 21, 211.

Laszlo, G., Archer, G.G., Darrell, J.H., Dawson, J.M. \& FletCHER, C.M. (1973) The diagnosis and prophylaxis of pulmonary complications of surgical operations. British Journal of Surgery, 60, 129.

MorRan, C. \& MCCARDle, C.S. (1980) The reduction of postoperative chest infection by prophylactic co-trimoxazole. British Journal of Surgery, 67, 464.

Morran, C., McNaught, W. \& McCarde, C.S. (1978) Prophylactic co-trimoxazole in biliary surgery. British Medical Journal, 2, 462.

O'Callaghan, C.H. \& Harding, S.M. (1977) The pharmacokinetics of cefuroxime in man in relation to its antibacterial activity. Proceedings of the Royal Society of Medicine, 70 (S.9), 4.

O'Callághan, C.H., Sykes, R.B., Griffiths, A. \& Thornton, J.E. (1976) Cefuroxime, a new cephalosporin antibiotic: activity in vitro. Antimicrobial Agents and Chemotherapy, 9, 511.

Polk, C.H. \& Lopez-Mayor, J.F. (1969) Postoperative wound infection: A prospective study of determinant factors and prevention. Surgery, 66, 97.

Presley, A.P. \& Alexander-Williams, J. (1974) Postoperative chest infection. British Journal of Surgery, 61, 448.

Stone, H.H., Haney, B.B., Kolb, L.D., Geheber, C.E. \& HOOPER, C.A. (1979) Prophylactic and preventive antibiotic therapy. Annals of Surgery, 189, 691.

Stone, H.H., Hooper, A.C., Kolb, L.D., Geheber, C E. \& DAwkINS, J.E. (1976) Antibiotic prophylaxis in gastric. biliary and colonic surgery. Annals of Surgery, 184, 443.

Strachan, C.J.L., BlaCK, J., Powis, S.J.A., WATERWORTh, T.A., Wise, R., WILKINSON, A.R., BuRdEN, D.W., Severn, M., Mitra, B. \& Norcott, H. (1977) Prophylactic use of cephazolin against wound sepsis after cholecystectomy. British Medical Journal, 1, 1254.

Wightman, J.A.K. (1968) A prospective survey of the incidence of post-operative pulmonary complications. British Journal of Surgery, 55, 85. 